九州大学学術情報リポジトリ

Kyushu University Institutional Repository

\title{
Effects of Enterobacteria (Burkholderia sp.) on Development of Riptortus pedestris
}

\section{Kil, Young Jong}

Department of Applied Biology, College of Agriculture and Life Science, Chungnam National University

Seo, Mi Ja

Department of Applied Biology, College of Agriculture and Life Science, Chungnam National University.

\section{Kang, Dong Kyun}

Department of Applied Biology, College of Agriculture and Life Science, Chungnam National University

Oh, San $\mathrm{Na}$

Department of Applied Biology, College of Agriculture and Life Science, Chungnam National University

他

https://doi.org/10.5109/1434382

出版情報：九州大学大学院農学研究院紀要. 59 (1)，pp.77-84，2014-02-28. Faculty of Agriculture， Kyushu University

バージョン：

権利関係 : 


\title{
Effects of Enterobacteria (Burkholderia sp.) on Development of Riptortus pedestris
}

\author{
Young Jong KIL ${ }^{1}$, Mi Ja SEO', Dong Kyun KANG ${ }^{1}$, San Na OH$^{1}$, Hyun Suk CHO', \\ Young Nam YOUN ${ }^{1}$, Chisa YASUNAGA-AOKI ${ }^{3}$ and Yong Man $\mathrm{YU}^{1 *}$
}

Laboratory of Insect Pathology and Microbial Control, Institute of Biological Control, Faculty of Agriculture, Kyushu University, Fukuoka 812-8581, Japan

(Received October 31, 2013 and accepted November 11, 2013)

\begin{abstract}
In order to investigate the effects of intestinal bacteria on biological characteristics of Riptortus pedestris, these bacteria were isolated and identified from the midgut of field population individuals in 5 outdoor areas and laboratory population. As the result of identification of intestinal bacteria, a total of 8 strains including genus Burkholderia were isolated. Burkholderia sp. was found in 5 all field populations, but there was no Burkholderia sp. in gut of laboratory population. As a result of investigation of growth inhibition of 4 antibiotics (penicillin, ofloxacin, streptomycin, and tetracycline) against isolated 9 intestinal bacteria, ofloxacin was selected as the antibiotic for inhibition of all intestinal bacteria in this study. Selected antibiotic, ofloxacin was treated on soil, the soybean seed, and the host plant and then was provided to $R$. pedestris as prey. In a result of examination of developmental periods of each larval stage, body length, the number of eggs, the first oviposition time, and hatchability rate of $R$. pedestris after ofloxacin treatment, it was shown that Burkholderia sp. did not affect the development of the host insect but the first oviposition time was in approximately $60 \%$ compared with a control group. Thus, it was thought that the presence of Burkholderia sp. strain affected the number of eggs and the first oviposition time of $R$. pedestris.
\end{abstract}

Key words: antibiotics, Burkholderia, Enterobacteria, Riptortus pedestris

\section{INTRODUCTION}

It has been reported that symbiotic strains that exist in natural ecosystems widely and organically related to other organisms such as animals and plants while they generally live with other microorganisms (Margulis and Fester, 1991; Ruby et al., 2004). Such symbiotic strains may play a role to be harmful to insects or as a critical pathogen, but on the other hand, they can play an essential and important role as they proliferate in the host through the symbiotic relationship. Among strains with such diverse symbiotic relationship, strains which live in the body of host and maintain the mutually close relationship are called endosymbiont and the symbiotic strains which affect the outside is called ectosymbiont (Kikuchi, 2009). Most insects naturally have symbiotic microorganisms in their midgut, coelom or cells, and they are generally maintained by specific transmission mechanism caused by host insects (Bourtzis and Miller, 2003; Buchner, 1965; Kikuchi, 2009; Bright and Bulgheresi, 2010).

Symbiotic microorganisms were investigated on juice of plants, fluids of vertebrates or midgut of monophagous insects like wood core. There are many cases in

\footnotetext{
1 Department of Applied Biology, College of Agriculture and Life Science, Chungnam National University, Daejeon 305-764, South Korea

2 Crop Environment Research Division, Rural Development Administration, National Institute of Crop Science, South Korea

${ }^{3}$ Laboratory of Insect Pathology and Microbial Control, Institute of Biological Control, Faculty of Agriculture, Kyushu University, 6-10-1 Hakozaki, Higashi-ku, Fukuoka, Fukuoka 812-8581, Japan

* Corresponding author (E-mail: ymyu@cnu.ac.kr)
}

which they topically exist in cells of insects eating foods in which nutrients are limited through growth period (Buchner, 1965). Symbiotic microorganisms have mainly been investigated in host insects, and vertically propagated through generations. They are sometimes not propagated outside the host's body. They are very diverse (Baumann and Baumann, 1994; Douglas, 1989). Most of symbiotic strains belong to the $\gamma$-Proteobacteria, and they are found in a wide variety of insects such as aphids, flies and Hemiptera. Most of these are absolute parasites or conditional parasites, and some strains can be cultured in the artificial media (Kikuchi, 2009).

Among symbiotic strains, Buchnera strain provides essential amino acids, and it is involved in the growth and reproduction as the absolute parasite. It is propagated to the later generations through transovarial transmission (Moran et al., 1993; Douglas, 1998; Miura et al., 2003). It is reported that symbiotic microorganism which is involved in the reproductive process of insects is Wolbachia ( $\alpha$-Proteobacteria) (Plantard et al., 1999). If the symbiotic bacteria are removed from aphids, the amino acid content is decreased in hemolymph so that growth rate is decreased and the weight of adults is also reduced (Pennachio et al., 1999).

Hemiptera are insects that undergo incomplete metamorphosis and more than 38,000 kinds are worldwide known (Schuh and Slater, 1995). Citrus junos fruit (Choi et al., 2000), and damage on sweet persimmon orchard have been reported in Korea (Lee et al., 2001). After the onset, reduction rate of seed is steadily decreasing due to damage on old insects. Thus, they are serious pests and bring adverse effects (Jung et al., 2010). Insects of Pentatomoidea have endosymbiont in intestines or topical cells, and the end of midgut or fourth section of midgut is characterized by several pockets or 
tubular sac. This sac is called crypts or cecum, and taxonomically divided into a variety of groups (Miyamoto, 1961; Buchner, 1965; Dasch et al., 1984). It is found that these crypts are full of bacteria, and the symbiotic strains exist (Kikuchi et al., 2005).

It is found that Burkholderia symbiotic strain which exists in crypts of Riptortus pedestris which is the insect of Pentatomoidea, major agricultural pest in Korea affects the growth such as length and abdomen of the host (Kikuchi et al., 2007)

In this study, bacteria that live in intestines of $R$. pedestris which is a major pest of leguminous crop are isolated and identified. Burkholderia sp. strains which are known as intestinal symbiotic bacteria are selected to review the physiological effect of this strain on $R$. pedestris.

\section{MATERIALS AND METHODS}

\section{Test insects}

Test insect, R. pedestris, was collected from different places. Four outdoor insect populations were collected from Pyeong-taek (P) and Yeon-cheon (E) in Gyeonggi, $\mathrm{Yu}-$ sung $(\mathrm{Y})$ in Daejeon and Hoeng-sung $(\mathrm{H})$ in Gangwon and one population was cultured over 20 successive generations in the insect physiology laboratory (L) in Chungnam National University. Total 5 populations were used in this experiment. Among them, P, E, Y, H and L populations were used to isolate and identify the bacteria. And Y population was used to examine the relationship with symbiotic bacteria. Culture conditions are as follows: Temperature of $25 \pm 2^{\circ} \mathrm{C}$, light conditions 16L: 8D and relative humidity of 50-60\%. They were cultured over successive generations for this experiment. Food for $R$. pedestris was the host plant in which hedge bean seeds were germinated and the seeds of Rhynchosia volubilis. They were cultured in the acrylic cage $(40 \times 44 \times 50 \mathrm{~cm})$.

\section{Isolation of Enterobacteria (Burkholderia sp.) in the digestive organ and $16 \mathrm{~S}$ rRNA sequence for identification}

Digestive organs of three adults of $R$. pedestris collected from each region were isolated according to modified methods which Moon et al. (2011) and Kikuchi (2009) used. After each population was put in it at $-20^{\circ} \mathrm{C}$ for 10 minutes to make it insensible, legs were removed and surface disinfection was carried out. For surface disinfection, after it was soaked in $70 \%(\mathrm{w} / \mathrm{w})$ ethanol for 1 minute and then it was put in $1 \% \mathrm{NaClO}_{3}$ for another one minute, it was treated once with sterile insect saline solution (9.32 g NaCl, $0.77 \mathrm{~g} \mathrm{KCl}, 0.5 \mathrm{~g} \mathrm{CaCl}_{2}, 0.18 \mathrm{~g}$ $\mathrm{NaHCO}_{3}, 0.01 \mathrm{~g} \mathrm{NaH}_{2} \mathrm{PO}_{4} / 1 \mathrm{~L}, \mathrm{pH}$ 7.4) to remove any excess ethanol on adult insect. After that, it was washed with sterile water once. After washing, it was placed on the top of paraffin filled with insect saline solution and fixed with pins. The midgut of $R$. pedestris was isolated under a dissecting microscope. Isolated midgut was put into $1.5 \mathrm{ml}$ Eppendorf tube (Axyzen, Central Avenue Union City. USA) in which $100 \mu \mathrm{l}$ of sterile water was added together with midgut of three insects and then crushed.
Crushed insect midgets were cultured on TSA (Bacto $^{\mathrm{TM}}$ Tryptic soybean Broth, Difco ${ }^{\mathrm{TM}}$ Agar) media and each of various bacteria which form the colony was isolated. A single colony which was purely cultured was used as a template for PCR. 518F (5'-CCA GCA GCC GCG GTA ATA CG-3') primer and 800R (5'-TAC CAG GGT ATC TAA TCC-3') primer were used. PCR was performed with the following reagents: 518 Forward primer, $1 \mu \mathrm{l}$; 800 Reverse primer, $1 \mu \mathrm{l}$; EF-Taq polymerase, $0.1 \mathrm{U}$; dNTPs, $1 \mu \mathrm{l}(2.5 \mathrm{mM}) ; 10 \times$ buffer, $3 \mu \mathrm{l}$; Template, $1 \mu \mathrm{l} ; \mathrm{H}_{2} \mathrm{O}, 22.9 \mu \mathrm{l}$. After all reagents were added into $0.2 \mathrm{ml}$ PCR tube and then mixed well, PCR (DNA Engine Tetrad 2 Peltier Thermal Cycler, BIO$\mathrm{RAD}$ ) was performed according to the following procedures: Initial denaturation at $95^{\circ} \mathrm{C}$ for 5 minutes, 35 cycles of denaturation at $94^{\circ} \mathrm{C}$ for 45 seconds, annealing at $55^{\circ} \mathrm{C}$ for 1 minute and extension at $72^{\circ} \mathrm{C}$ for 1 minute, and final extension at $72^{\circ} \mathrm{C}$ for 10 minutes. PCR primers and dNTPs were removed by using the PCR Clean-up kit (Millipore) and then PCR products were purified. Purified PCR products were sequenced by using the Big Dye Terminator Cycle Sequencing Kit v.3.1 (Applied Biosystems, USA). The homology of determined $16 \mathrm{~S}$ rRNA sequence was compared by using BLAST program of NCBI/ Gene Bank database.

\section{Investigation on susceptibility of Enterobacteria (Burkholderia sp.) by antibiotic treatment}

Single colony from strains cultured by streaking it on each medium was selected and then cultured on general TSB media or TSB media with antibiotics through smear culture to examine the degree of inhibition. Four kinds of antibiotics such as penicillin (Sigma, USA), ofloxacin (Sigma, USA), tetracycline (Sigma, USA) and streptomycin (Sigma, USA) which belonged to penicillin, quinolone, tetracycline and aminoglycoside series, respectively, were used to make the media at the final concentration of $0.01 \%$. They were cultured at $25^{\circ} \mathrm{C}$ for 10 days. The result showed that isolated 9 strains were all inhibited on media containing ofloxacin. Therefore, it was selected as the antibiotic used to study the effect on growth of $R$. pedestris in the absence of Enterobacteria (Burkholderia sp.).

\section{Effect of Burkholderia sp. strains and intestinal bacteriaon growth of $R$. pedestris and physiologi- cal characteristics}

In order to investigate the symbiotic relationship between Burkholderia sp. strains and $R$. pedestris, $R$. pedestris were cultured with both host plant (hedge bean) and seeds (yak-kong) at the same time. Developmental and physiological characteristics such as developmental period, length of adult, egg production rate and the hatchability rate were examined. For $R$. pedestris used in the experiment, nymph at 1st stage hatched from one egg of adult population collected in Yuseong was cultured on the Insect dish $(100 \times 40 \mathrm{~mm}$ diameter, SPL Life science, Korea) and mass cultured in the acrylic cage for evaluation.

For individual rearing experiments, two insects were 
cultured on insect dish. In order to kill all bacteria living in the midgut of $R$. pedestris, the surface disinfection was performed on foods such as hedge bean host plant and yak-kong seeds with 100\% ethanol for 5 minutes, and host plant treated with $100 \mu \mathrm{g} / \mathrm{ml}$ of ofloxacin and bean seeds soaked in $100 \mu \mathrm{g} / \mathrm{ml}$ of antibiotics for 5 minutes were supplied as the food. In addition, bean host and seeds in which Burkholderia sp. strain was treated at the concentration of $10^{6} \mathrm{cfu} / \mathrm{ml}$ were supplied as the food in the treated group used in this experiment. Beans and seeds treated with sterile water were supplied in the control group. For acrylic cage experiments, beans germinated from seeds planted on sterile bed soil and bean seeds in which surface disinfection was carried out were put in the acrylic cage $(45 \times 45 \times 45 \mathrm{~cm})$, and 50 nymphs at the first stage were put in each experimental group. Statistical analysis of data obtained from each population was performed by using one way ANOVA of PASW statistics 18 program.

\section{RESULTS AND DISCUSSION}

Enterobacteria (Burkholderia sp.) of R. pedestris

Outdoor adults of $R$. pedestris used as the test insect were collected from four different regions such as
Pyeong-taek and Yeon-cheon in Gyeonggi, Yu-sung in Daejeon and Hoeng-sung in Gangwon from June 2011 to July 2011 using the pheromone traps. On the other hands, for indoor successive rearing, host plants in which seeds of hedge bean were germinated and Yak-kong (Rhynchosia volubilis) were supplied as the food, and adults of $R$. pedestris were distributed from the insect physiology laboratory in the department of applied biology, Chungnam National University.

The midgut was isolated from above insects. Isolated midgut was cultured on TSA media (Ronald, 2004), and 16S rRNA sequences of purely isolated Enterobacteria (Burkholderia sp.) were analyzed and compared by using BLAST search (Table 1). As the result of isolating and identifying each single colony on the media, it was shown that a total of nine kinds such as three, five, two, two and two kinds were isolated from the populations of Pyeong-taek, Yu-sung, Hoeng-sung, Yeon-cheon, and laboratory population, respectively. It was confirmed that Burkholderia sp. strain was included in all four regions excluding laboratory population (Table 2). Genetic relationships of identified Burkholderia sp. strain were examined through the phylogenetic tree, and it was confirmed that it had the close relationships with other uncultured Burkholderia sp. symbiotic strains (Fig. 1).

Table 1. Phylogenetic analysis of enterobacteria isolated from gut of $R$. pedestris

\begin{tabular}{llc}
\hline \multicolumn{1}{c}{ Blast search } & \multicolumn{1}{c}{ Collection sites } & Similarity (\%) \\
\hline Burkholderia sp. & Hoeng-sung, Pyeong-taek, Yeon-cheon, Yu-sung & 99 \\
Ascomycota sp. & Pyeong-taek & 99 \\
Chryseobacterium sp. & Yu-sung & 98 \\
Enterococcus & Laboratory & 99 \\
Klebsiella sp. & Hoeng-sung, Yu-sung & 99 \\
Microbacterium sp. & Pyeong-taek & 99 \\
Pseudomonas sp. & Yeon-cheon, Yu-sung & 98 \\
Serratia marcescens & Yu-sung & 99 \\
Yokenella regensburgei & Laboratory & 99 \\
\hline
\end{tabular}

Table 2. Other gut bacteria including Burkholderia sp. detected from $R$. pedestris adults collected in fields

\begin{tabular}{|c|c|c|c|c|c|c|}
\hline Samples & $\mathrm{P}$ & $\mathrm{Y}$ & $\mathrm{H}$ & $\mathrm{E}$ & $\mathrm{L}$ & Total \\
\hline Burkholderia sp. & + & + & + & + & - & 4 \\
\hline Ascomycota sp. & + & - & - & - & - & 1 \\
\hline Chryseobacterium sp. & - & + & - & - & - & 1 \\
\hline Enterococcus & - & - & - & - & + & 1 \\
\hline Klebsiella sp. & - & + & + & - & - & 2 \\
\hline Microbacterium sp. & + & - & - & - & - & 1 \\
\hline Pseudomonas sp. & - & + & - & + & - & 2 \\
\hline Serratia marcescens & - & + & - & - & - & 1 \\
\hline Yokenella regensburgei & - & - & - & - & + & 1 \\
\hline 9 species & 3 & 5 & 2 & 2 & 2 & \\
\hline
\end{tabular}

+ : positive, - : negative

P: Pyeong-taek, Y: Yu-sung, H: Hoeng-sung, E: Yeon-cheon, L: Laboratory 


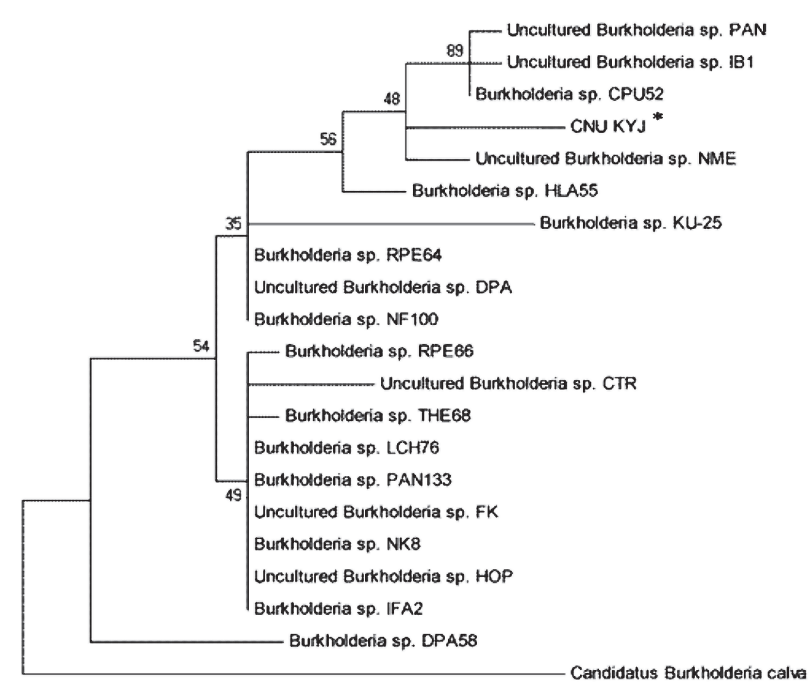

$\longmapsto 0.002$

Fig. 1. Phylogenetic tree based on $16 \mathrm{~S}$ rRNA gene sequence comparison showing the position of strains Burkholderia sp. CNU KYJ and other related species of the genus Burkholderia.

\section{Susceptibility of antibiotics of Enterobacteria (Burkholderia sp.)}

The physiological changes were examined after the growth of $R$. pedestris was inhibited with antibiotics of the Enterobacteria (Burkholderia sp.). Koga et al. (2003) used ampicillin of penicillin series and rifampicin of ansamycin series with strong antimicrobial activity against Gram positive bacteria in order to investigate the effects on symbiotic bacteria after absolute symbiotic bacteria were inhibited with antibiotics. The antibiotics used in this experiment were 4 kinds such as penicillin, ofloxacin, tetracycline and streptomycin. It was well known that penicillin inhibited biosynthesis of cell wall of bacteria and it had inhibitory effect to most of Gram positive bacteria as the representative antibiotic of penicillin series. Ofloxacin which inhibited DNA synthesis of bacteria, and tetracycline which inhibited protein synthesis were antibiotics of quinolone series and tetracycline series, respectively. They had antimicrobial activity against Gram negative and positive bacteria. In addition, streptomycin was the antibiotic of aminoglycoside series, and it had effect to inhibit the protein synthesis of bacteria and antimicrobial activity against Gram negative Enterobacteria (Burkholderia sp.) (Moon et al., 2011).

In this experiment, 9 kinds of Enterobacteria (Burkholderia sp.) were cultured on TSA media with a final concentration of $0.01 \%$ of antibiotics such as penicillin, ofloxacin, tetracycline and streptomycin. The results showed that Chryseobacterium sp. and 2 other species were not inhibited on media without penicillin antibiotic. Klebsiella sp. and 2 other species, and Chryseobacterium sp. and 4 other species were not inhibited on media with streptomycin and tetracycline antibiotics, respectively. They formed colonies so that they were identified as resistant bacteria. However, any colonies were observed for 10 days on media with ofloxacin antibiotic (Table 3). In addition, bacteria with susceptibility to all 4 kinds of antibiotics were Burkholderia sp., Ascomycota sp., Pseudomonas sp. and Yokenella regensburgei. In order to examine the effect of $R$. pedestris on the Enterobacteria (Burkholderia sp.), ofloxacin antibiotic which was susceptible to all nine kinds was selected and the experiment was carried out with it.

\section{Physiological effect of ofloxacin antibiotic on $\boldsymbol{R}$. pedestris}

The purpose of this study was to investigate the effect of antibiotics on microorganisms that inhabited in the intestine of $R$. pedestris. As ofloxacin antibiotic which appeared to inhibit the isolated 9 species of bacteria was given, the developmental period of nymphs by each larval stage, the length of adults, the first oviposition time, the number of eggs and the hatchability rate were examined. In order to examine the difference of developmental period and length of adults in female and male, they were separated, compared and analyzed.

$R$. pedestris typically became adults through nymph periods of first stage through fifth stage. The molt period was increased as it got older. The period of nymph was about 20 days (Bae et al., 2009). The results of examination of $R$. pedestris used in this experiment were as fol-

Table 3. Inhibition effects of 4 antibiotics against 5 main gut bacteria from $R$. pedestris

\begin{tabular}{|c|c|c|c|c|c|}
\hline Strains & Penicillin & Ofloxacin & Streptomycin & Tetracycline & TSA \\
\hline Burkholderia sp. & - & - & - & - & +++ \\
\hline Ascomycota sp. & - & - & - & - & +++ \\
\hline Chryseobacterium sp. & + & - & - & + & +++ \\
\hline Enterococcus & - & - & + & + & +++ \\
\hline Klebsiella sp. & - & - & + & + & +++ \\
\hline Microbacterium sp. & + & - & - & + & +++ \\
\hline Pseudomonas sp. & - & - & - & - & +++ \\
\hline Serratia marcescens & ++ & - & + & ++ & +++ \\
\hline Yokenella regensburgei & - & - & - & - & +++ \\
\hline
\end{tabular}

- : No growth, $+:$ 1 3 mm, ++ : 3 10 mm, +++ : over $10 \mathrm{~mm} / \mathrm{TSA}$ medium 
lows. No treatment group of female $R$. pedestris had $2.2 \pm 3.9$ days for second stage, $2.3 \pm 0.5$ days for third stage, $2.8 \pm 0.9$ days for fourth stage, 3.8 \pm 1.1 days for fifth stage and $4.1 \pm 1.3$ days for adults, respectively. Group treated with ofloxacin antibiotic had $2.0 \pm 4.5$ days for second stage, $2.2 \pm 0.4$ for third stage, $2.5 \pm 0.7$ days for fourth stage, $3.1 \pm 0.9$ days for fifth stage and $5.5 \pm 1.5$ days for adults, respectively. Thus, it was confirmed that there was no effect of ofloxacin antibiotic on the developmental period of female (Table 4). In case of males, no treatment group of had $2.1 \pm 0.3$ days for second stage, $2.1 \pm 0.3$ for third stage, $3.1 \pm 1.1$ days for fourth stage, $3.5 \pm 1.4$ days for fifth stage and $4.3 \pm 1.1$ days for adults, respectively. Group treated with ofloxacin antibiotic had 1.9 \pm 0.4 days for second stage, $2.0 \pm 0$ days for third stage, $2.9 \pm 0.6$ days for fourth stage, $3.3 \pm 0.7$ days for fifth stage and $5.4 \pm 1.7$ days for adults, respectively. Like the results of females, it was confirmed that there was no significant difference in the developmental period of males. In addition, it was found that relatively similar time was spent between females and males. Through this result, it was found that the time of nymphs by each larval stage was a little bit different, but the molt period became longer as it went to the later stages.

We would like to check whether the treatment of ofloxacin antibiotic which killed all bacteria in midgut affected the developments of females and males of $R$.

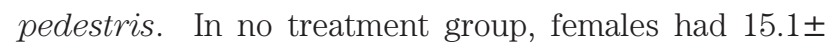
$0.4 \mathrm{~mm}$, and males had $15.3 \pm 0.3 \mathrm{~mm}$. In the group treated with ofloxacin, females had $15.1 \pm 0.3 \mathrm{~mm}$, and males had $14.9 \pm 1.0 \mathrm{~mm}$. There was no significant difference between males and females. However, in no treatment group and a group treated with ofloxacin, there was the difference in male adults. A group treated with ofloxacin showed a little bit shorter length (Table 5). This result seemed to be caused by the difference between no treatment group and a group treated with antibiotic, because host insect was affected by ofloxacin antibiotic. It was reported that treatment with antibiotic or host environment which was not suitable for intestinal bacteria to inhabit in the host affected the physiological factors such as development or spawning of host insects (Lockwood and Story, 1986; Pardo et al., 2006; Pardo and Almeida, 2009). In addition, the results in which the density of intestinal bacteria was decreased by antibiotic treatment and the survival of host insects was affected

Table 4. Effects of antibiotics and Burkholderia sp. on development of R. pedestris

\begin{tabular}{|c|c|c|c|c|c|}
\hline \multirow{2}{*}{ Sex } & \multirow{2}{*}{ Stage } & \multicolumn{4}{|c|}{ Developmental periods (days) } \\
\hline & & Antibiotics (Ofloxacin) & Burkholderia sp. & Control & $\mathrm{P}$ \\
\hline \multirow{5}{*}{ Female } & 2nd & $2.0 \pm 4.5 \mathrm{a}$ & $2.0 \pm 0.0 \mathrm{a}$ & $2.2 \pm 3.9 \mathrm{a}$ & 0.539 \\
\hline & $3 \mathrm{rd}$ & $2.2 \pm 0.4 \mathrm{a}$ & $2.4 \pm 0.5 \mathrm{a}$ & $2.3 \pm 0.5 \mathrm{a}$ & 0.599 \\
\hline & 4 th & $2.5 \pm 0.7 \mathrm{a}$ & $4.3 \pm 2.5 b$ & $2.8 \pm 0.9 \mathrm{a}$ & $0.049 *$ \\
\hline & 5 th & $3.1 \pm 0.9 \mathrm{a}$ & $4.4 \pm 3.9 \mathrm{a}$ & $3.8 \pm 1.1 \mathrm{a}$ & 0.587 \\
\hline & adults & $5.5 \pm 1.5 \mathrm{a}$ & $4.9 \pm 2.3 \mathrm{a}$ & $4.1 \pm 1.3 \mathrm{a}$ & 0.214 \\
\hline \multirow{5}{*}{ Male } & 2nd & $1.9 \pm 0.4 \mathrm{a}$ & $2.1 \pm 0.4 \mathrm{a}$ & $2.1 \pm 0.3 \mathrm{a}$ & 0.379 \\
\hline & 3rd & $2.0 \pm 0.0 \mathrm{a}$ & $2.8 \pm 1.3 \mathrm{~b}$ & $2.1 \pm 0.3 \mathrm{a}$ & 0.090 \\
\hline & 4 th & $2.9 \pm 0.6 \mathrm{a}$ & $4.8 \pm 2.3 \mathrm{~b}$ & $3.1 \pm 1.1 \mathrm{a}$ & $0.017^{*}$ \\
\hline & 5 th & $3.3 \pm 0.7 \mathrm{a}$ & $3.0 \pm 1.1 \mathrm{a}$ & $3.5 \pm 1.4 \mathrm{a}$ & 0.263 \\
\hline & adults & $5.4 \pm 1.7 \mathrm{a}$ & $4.6 \pm 0.7 \mathrm{a}$ & $4.3 \pm 1.1 \mathrm{a}$ & 0.291 \\
\hline
\end{tabular}

Values represent mean $\pm \mathrm{SD}$. Different letters at values in rows show significant different (One-way ANOVA, Post Hoc Tests by Duncan) in PASW Statistics 18, P<0.05, *: significant

Table 5. Effects of antibiotics and Burkholderia sp. on body lengths of $R$. pedestris

\begin{tabular}{|c|c|c|c|c|c|}
\hline \multirow{2}{*}{$\begin{array}{l}\text { Rearing } \\
\text { methods }\end{array}$} & \multirow{2}{*}{ Sex } & \multicolumn{4}{|c|}{ Body lengths (mm) } \\
\hline & & Antibiotics (Ofloxacin) & Burkholderia sp. & Control & $\mathrm{P}$ \\
\hline \multirow{2}{*}{$\begin{array}{l}\text { Individual } \\
\text { rearing }\end{array}$} & Female & $15.1 \pm 0.3 \mathrm{a}$ & $15.0 \pm 0.4 \mathrm{a}$ & $15.1 \pm 0.4 \mathrm{a}$ & 0.258 \\
\hline & Male & $14.9 \pm 1.0 \mathrm{a}$ & $15.1 \pm 0.3 \mathrm{a}$ & $15.3 \pm 0.3 \mathrm{a}$ & 0.101 \\
\hline \multirow{3}{*}{ Mass rearing } & Female & $14.8 \pm 0.4 \mathrm{a}$ & $14.9 \pm 0.4 \mathrm{a}$ & $15.4 \pm 0.5 b$ & $0.006^{*}$ \\
\hline & Male & $14.7 \pm 0.6 \mathrm{a}$ & $15.1 \pm 0.4 \mathrm{~b}$ & $15.5 \pm 0.4 \mathrm{c}$ & $0.000^{*}$ \\
\hline & Hatch rate (\%) & $16.0 \pm 3.0 \mathrm{~b}$ & $64.7 \pm 9.1 \mathrm{a}$ & $75.8 \pm 11.0 \mathrm{a}$ & $0.000^{*}$ \\
\hline
\end{tabular}

Values represent mean $\pm \mathrm{SD}$. Different letters at values in rows show significant different (One-way ANOVA, Post Hoc Tests by Duncan) in PASW Statistics 18, P<0.05, *: significant

a) In individual rearing, one bug was tested in insect breeding dish whereas several bugs were reared in acryl cage in mass rearing. 
Table 6. Effects of antibiotics and Burkholderia sp. on fecundity of R. pedestris

\begin{tabular}{lcccc}
\hline & Antibiotics (Ofloxacin) & Burkholderia sp. & Control & $\mathrm{P}$ \\
\hline The first oviposition time & $7.2 \pm 2.2 \mathrm{~b}$ & $4.1 \pm 0.4 \mathrm{a}$ & $5.3 \pm 1.6 \mathrm{a}$ & $0.030^{*}$ \\
Average number of eggs & $13.0 \pm 20.0 \mathrm{a}$ & $42.3 \pm 31.2 \mathrm{a}$ & $28.1 \pm 24.1 \mathrm{a}$ & 0.273 \\
\hline
\end{tabular}

Values represent mean \pm SD. Different letters at values in rows show significant different (One-way ANOVA, Post Hoc Tests by Duncan) in PASW Statistics $18, \mathrm{P}<0.05$, *: significant

by the concentration of antibiotic treatment were presented (Seo and Kim, 2010). Further review will be needed to see if this result is caused by the absence of intestinal bacteria due to antibiotic or by the treatment of antibiotic in the future.

The first oviposition time of $R$. pedestris was $5.3 \pm$ 1.6 days for females in no treatment group and $7.2 \pm 2.2$ days for females in a group treated with ofloxacin. Average number of eggs was $28.1 \pm 24.1$ in no treatment group and $13.0 \pm 20.0$ in a group treated with ofloxacin. There was no significance in average number of eggs between groups, but there was the difference in numbers. A group treated with antibiotic had longer oviposition time compared with no treatment group, and it showed statistically significant difference (Table 6). According to results of Mittler's study (Mittler, 1971), it was found that the growth of aphids, host, was slow down and negative effect was given to the spawning, when the number of Buchnera symbiotic bacteria was decreased by giving the treatment of tetracycline antibiotic to food of aphids.

The results of mass rearing of $R$. pedestris in the acrylic cage were as follows. In no treatment group, the length of females and males was $15.4 \pm 0.5 \mathrm{~mm}$, and $15.5 \pm 0.4 \mathrm{~mm}$, respectively. In a group treated with ofloxacin, the length of females and males was $14.8 \pm 0.4$ $\mathrm{mm}$, and $14.7 \pm 0.6 \mathrm{~mm}$, respectively. There was significant difference. In addition, the hatchability rate of no treatment group and a group treated with ofloxacin was $75.8 \pm 11.0$ and $16.0 \pm 3.0$, respectively. It showed the big difference (Table 5). Thus, it was determined that the absence of symbiotic bacteria and intestinal bacteria caused by treatment of antibiotics affected the hatchability rate of $R$. pedestris.

\section{Effect of Burkholderia sp. strains on $R$. pedestris}

Burkholderia sp. strains isolated from the intestines of $R$. pedestris were isolated from all four populations collected from the outdoor, but it was not found in population with successive rearing in the indoor. Thus, we examined whether Burkholderia sp. strain affected the development and physiological characteristics of host insect, $R$. pedestris as it inhabited in the host insect. In order to remove the enterobacteria within the midgut of $R$. pedestris to be used in the experiment, eggs of each population were disinfected with ethanol prior to hatching the egg. After disinfection of eggs, hatched nymphs in the first stage were ground to examine whether the enterobacteria were not present. Bean seeds and host plants treated with Burkholderia sp. strain were supplied for the food. Food treated with strains was supplied to
R. pedestris, and developmental period of nymph at each larval stage, the length of adults, the first oviposition time, the number of eggs and hatchability rate were examined.

In a group treated with Burkholderia sp. strain present in $R$. pedestris in four regions, the developmental period of females by each larval stage was as follows: $2.0 \pm 0.0$ days for second stage, $2.4 \pm 0.5$ days for third stage, $4.4 \pm 3.9$ days for fifth stage and $4.9 \pm 2.3$ days for adults. There was no significance compared with no treatment group. However, a group treated with Burkholderia sp. strain had 4.3 \pm 2.5 days for fourth stage of nymph, which showed statistical significance (Table 4). Developmental period of males at each stage showed the same pattern of females. There was no significant difference in a group treated with Burkholderia sp. strain or antibiotics and no treatment group. However, it was found that the developmental period tended to be increased in a group treated with Burkholderia sp. strain at fourth stage of nymph. The developmental period of $R$. pedestris tended to be increased as it went to the later stage. It was reported that the developmental period of nymph at fourth stage was generally 4.4-6.9 days (Bae et al., 2004). Therefore, we can guess that R. pedestris grows normally due to treated Burkholderia sp. strain.

Meanwhile, the effect of Burkholderia sp. in $R$. pedestris on degree of development of length of female and male adult insects was examined. The results from rearing several species in the acrylic cage showed that the length of male adults in a group treated with Burkholderia sp. strain was a bit longer than males in a group treated with antibiotics, which showed statistically significant difference. However, it was found that Burkholderia sp. strain did not affect the development of both females and males (Table 5).

The first oviposition time and the number of eggs were examined to investigate the effect of Burkholderia sp. in $R$. pedestris on reproduction. The results showed that the average first oviposition time was as long as 7.2 days in the absence of Burkholderia sp. caused by the treatment of ofloxacin antibiotic. However, it was shown

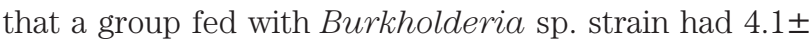
$0.4 \mathrm{a}$ or no treatment group had $5.3 \pm 1.6 \mathrm{a}$. Thus, it was thought that it affected the spawning. In addition, the average number of eggs was 13.0 in a group treated with antibiotic, which was smaller than the average number of eggs of 42.3 in a group treated with Burkholderia sp. strain. Thus, it was shown that it affected the number of eggs but it was not statistically significant (Table 6). On the other hands, there was no difference in the hatcha- 
bility rate (Table 5 ).

Moon et al. (2011) found that the weight of pupa tended to be decreased in a group of aphids treated with Staphylococcus saprophyticus strain isolated as the intestinal bacteria of ladybug compared with a group treated with antibiotics. Thus, they reported that the intestinal bacteria affected the growth of host insects. Moreover, it gave the positive effects on the number of eggs or the hatchability rate compared with ladybug treated with antibiotics to remove intestinal bacteria, $S$. saprophyticus. Thus, they suggested that the intestinal bacteria were likely to be involved in reproduction of host insects. In the result of this study, Burkholderia sp. strain identified as the intestinal bacteria of $R$. pedestris was not clearly found to affect the development of host insects, but it was likely to affect the reproduction.

According to Kikuchi et al. (2007) and Kikuchi (2009), the length of adult insects in a group treated with Burkholderia sp. strain was longer by about $1 \mathrm{~mm}$ compared with that in no treatment group, but striking difference was not shown in this study. On the other hands, it was found that the number of eggs tended to be increased upon treatment with Burkholderia sp. strain. In addition, a group treated with ofloxacin antibiotic showed the markedly low numbers of the first oviposition time, the number of eggs and hatchability rate compared with those in no treatment group and a group treated with Burkholderia sp. strain. This result showed that Burkholderia sp. symbiotic strain and intestinal bacteria of $R$. pedestris could affect the reproduction of $R$. pedestris. Through these findings, the further study to investigate which relationship of symbiotic bacteria and intestinal bacteria with host insects carries out the mechanism will be required.

\section{ACKNOWLEDGEMENTS}

This paper is made on the basis of the results obtained while 2013 joint research project in Rural Development Administration [assessment of effect of green manure crop cultivation on agricultural environment (PJ006512132011)].

\section{REFERENCES}

Bae, S. D., H. J. Kim., C. G. Park and J. K. Jung 2004 Comparison of the nymphal development, adult longevity and oviposition of the bean bug, Riptortus clavatus Thunberg (Hemiptera: Alydidae) in fibrous nylon and glass-tube. Korean J. Appl. Entomol., 43: 275-279

Bae, S. D., H. J. Kim, Y. N. Yoon, S. T. Park, B. R. Choi and J. K. Jung 2009 Effect of a Mungbean cultivar, Jangannogkdu on nymphal development, adult longevity and oviposition of soybean stink bugs. Koeran J. Appl. Entomol., 48: 311-318

Baumann, L. and P. Baumann 1994 Growth kinetics of the endosymbionts Buchnera aphidicola in the aphid Schizaphis graminum. Appl. Environ. Microbiol., 60: 3440-3443

Bourtzis, K. and T. A. Miller 2003 Insect symbiosis. CRC press: Boca Raton, F. L.

Bright, M. and S. Bulgheresi 2010 A complex journey: transmis- sion of microbial symbionts. Nat. Rev. Microbiol., 8: 218-230

Buchner, P. 1965 Endosymbiosis of animals with plant microorganisms. Interscience Publishers, New York

Choi, D. S., K. C. Kim and K. C. Lim 2000 The status of spot damage and fruit piercing pests on Yuzu (Citursjunos) fruit. Koeran J. Appl. Entomol., 39: 259-266

Dasch G. A., Weiss A. E., Chang K. P. 1984. Endosymbionts of insects. In "Bergey's Manual of Systematic Bacteriology," Vol. 1, ed. by N. R. Kreig and J. G. Holt, Baltimore, Md., Williams \& Wilkins, pp. 811-833

Douglas, A. E. 1989 Mycetocyte symbiosis in insect. Biol. Rev. 64: $409-434$

Douglas, A. E 1998 Nutritional interactions in insect microbial symbioses: Aphids and their symbiotic bacteria. Buchnera. Annu. Rev. Entomol., 43: 17-37

Jung, J. K., B. Y. Seo, J. T. Youn, J. H. Park and J. R. Cho 2010 Injury of full seed stage soybeans by the bean bug, Riptortus pedestris. Koeran J. Appl. Entomol., 49: 265-432

Kikuchi, Y. 2009 Endosymbiotic bacteria in insects: Their diversity and culturability. Microbes Environ., 24: 195-204

Kikuchi, Y., H. Takahiro and F. Takema 2007 Insect-microbe mutualism without vertical transmission: A stinkbug acquires a beneficial gut symbiont from the environment every generation. Appl. Environ. Microbiol., 73: 4308-4316

Kikuchi, Y., Y. M. Xian and F. Takema 2005 Gut symbiotic bacteria of the genus Burkholderia in the broad-headed bugs Riptortus clavatus and Leptocorisa chinensis (Heteroptera: Alydidae). Appl. Environ. Microbiol., 71: 4035-4043

Koga, R., T. Tsuchida and T. Fukatsu 2003 Changing partners in an obligate symbiosis: a facultative endosymbiont can compenste for loss of the essential endosymbiont Buchnera in an aphid. Proc. R. Soc. Lond., B. 270: 2543-2550

Lee, D. W., G. C. Lee, S. W. Lee, C. G. Park, H. Y. Choo and C. H. Shin 2001 Survey on pest management practicesurve scheme of increasing income in sweet persimmon farms in area. Korea J. Pest Sci., 5: 1-86

Lockwood, J. A. and R. N. Story 1986 Adaptive function of nymphal aggregation in the southern green stink bug, Nezara viridula (L.) (Hemiptera: Pentatomidea). Environ. Entomol. 15: $739-749$

Margulis, L. and R. Fester 1991 Symbiosis as a source of evolutionary innovation. MIT Press, Cambridge, MA.

Mittler, T. E. 1971 Dietary amino acid requirement of the aphid Myzus persicae affected by antibiotics uptake. J. Nutrition, 101: $1023-1028$

Miura, T., C. Braendle, A. shingleton, G. Sisk, S. Kambhampati and D. L. Stern 2003 A comparison of parthenogenetic and sexual embryogenesis of the pea aphid Acyrthosiphon pisum (Hemiptera: Aphidoidea). J. Exp. Zool., 295: 59-81

Miyamoto, S. 1961 Comparative morphology alimentary organs of Heteroptera, with the phylogenetic consideration. Sieboldia, 2: $197-259$

Moon, C. W., K. K. Kim, K. S. Whang, M. J. Seo, Y. N. Youn and Y. M Yu 2011 Characteristics of enterobacteria from Harmonia axyridis and effects of Staphylococcus spp. on development of H. axyridis. Koeran J. Appl. Entomol., 50: 157-165

Moran, N. A., M. A. Munson, P. Baumann and H. Ishikawa 1993 Molecular clock in endosymbiotic bacteria is calibrated using the insect host. Proc. R. Soc. Lond., 235: 167-171

Pardo, S. S. and R. P. P. Almeida 2009 Phylogenetic placement of 
pentatomid stink bug gut symbiont. Curr. Microbiol., 58: 64-69

Pardo, S. S., D. Rubinoff and R. P. P. Almeida 2006 Vertical transmission of a pentatomid caeca-associated symbiont. Ann. Entomol. Soc. Am., 99: 577-585

Pennacchio, F., F. Paolo, F.Falabella, M. C. Digilio, F. Bisaccia and E. Tremblay 1999 Development and nutrition of the braconid wasp, Aphidiuservi in aposymbiotic host aphids. Arch. Insect Biochem. Physiol., 40: 53-63

Plantard, O., J. A. Rasplus, G. Mondor, I. L. Clainche and M. Solignac 1999 Distribution and phylogeny of Wolbachia inducing thelytoky in Rhoditini and 'Aylacini' (Hymenoptera: Cynipidae).
Insect Mol. Biol., 8: 185-191

Ronald, M. 2004 Microbiological Media. CRC Press, Boca Raton, FL.

Ruby, E., B. Henderson and M. McFall-Ngai 2004 We get by with a little help from our (little) friends. Science, 303: 1305-1307

Schuh, R. T. and J. A. Slater 1995 True bugs of the world (Hemiptera: Heteroptera). Cornell Univ. Press, New York

Seo, S. Y. and Y. G. Kim 2010 Antibiotic and insecticidal activities of metabolites derived from an entomopathogenic bacterium, Xenorhadus nematophila, against the bean bug, Riptortus clavatus. Koeran J. Appl. Entomol., 49: 251-259 